\title{
Análise da detecção de mudança na paisagem ocasionada pela construção da Usina Hidrelétrica das Três Gargantas - Yiling, Hubei, China
}

\begin{abstract}
Analysis of landscape change detection caused by the construction of the Three Gorges Hydroelectric Power Station - Yiling, Hubei, China
\end{abstract}

Análisis de la detección de cambios en el paisaje causados por la construcción de la central hidroeléctrica de las Tres Gargantas - Yiling, Hubei, China

\author{
Bianca Rodrigues Vieira \\ Discente, UNESP, Brasil. \\ bianca.r.vieira@unesp.br \\ Leandro Lopes dos Santos \\ Discente, UNESP, Brasil. \\ leandro.lopes@unesp.br \\ Sandra Medina Benini \\ Docente da FCT/UNESP, Brasil. \\ arquiteta.benini@gmail.com
}




\section{Revista Científica ANAP Brasil}

ISSN 1984-3240 - Volume 14, número 34, 2021

\section{RESUMO}

As diferentes técnicas vinculadas às geotecnologias são de suma importância para identificação e monitoramento de diferentes fenômenos, sendo eles de natureza antrópica ou não. Neste contexto, este artigo teve como objetivo analisar os impactos ambientais da instalação da Usina Hidrelétrica das Três Gargantas - Yiling, Hubei, China, considerando a alteração da paisagem decorrentes do processo de inundação na área de implantação do reservatório, por meio da aplicação do Índice da Diferença Normalizada da Água (NDWI) em uma série temporal do Landsat-5, considerando os anos de 1993 e 2005. Por intermédio dessa ferramenta, constatou-se que houve uma considerável alteração na paisagem, sendo elas: o cursor original do canal sofreu fortes modificações, bem como em função do barramento das águas, a composição florística local sofreu uma considerável perda. Por meio deste estudo, verificouse que a área alagada estimada é de $16.608 \mathrm{~km}^{2}$.

PALAVRAS-CHAVE: Geotecnologias. Usina Hidrelétrica das Três Gargantas, China. Índice da Diferença Normalizada da Água (NDWI).

\section{ABSTRACT}

The different techniques linked to geotechnologies are extremely important for the identification and monitoring of different phenomena, whether anthropic or not. Thus, this article aimed to analyze the environmental impacts of the installation of the Três Gorges Hydroelectric Power Plant - Yiling, Hubei, China, considering the change in the landscape resulting from the flooding process in the area of reservoir implementation, through the application of the Index of the Normalized Water Difference (NDWI) in a Landsat-5 time series, considering the years 1993 and 2005. Through this tool, it was found that there was a considerable change in the landscape, namely: the original cursor of the channel suffered strong modifications, as well as due to the damming of the waters, the local floristic composition suffered a considerable loss. Through this study, it was verified that the estimated flooded area is $16,608 \mathrm{~km}^{2}$.

KEYWORDS: Geotechnologies. Three Gorges Hydroelectric Power Plant, China. Normalized Water Difference Index (NDWI).

\section{RESUMEN}

Las diferentes técnicas vinculadas a las geotecnologías son sumamente importantes para la identificación y el seguimiento de diferentes fenómenos, antrópicos o no. Así, este artículo tuvo como objetivo analizar los impactos ambientales de la instalación de la Central Hidroeléctrica Três Gorges - Yiling, Hubei, China, considerando el cambio en el paisaje resultante del proceso de inundación en el área de implementación del embalse, a través de la aplicación del Índice de Diferencia Normalizada del Agua (NDWI) en una serie de tiempo Landsat-5, considerando los años 1993 y 2005. A través de esta herramienta, se comprobó que hubo un cambio considerable en el paisaje, a saber: el cursor original del canal sufrió fuertes modificaciones, así como debido al represamiento de las aguas, la composición florística local sufrió una pérdida considerable. A través de este estudio, se descubrió que la zona inundada estimada es de $16.608 \mathrm{~km}^{2}$.

PALABRAS CLAVE: Geotecnologías. Central hidroeléctrica Three Gorges, China. Índice de diferencia de agua normalizado (NDWI). 


\section{Revista Científica ANAP Brasil}

ISSN 1984-3240 - Volume 14, número 34, 2021

\section{INTRODUÇÃO}

Segundo Campos et al. (2018, p. 01), o “[...] uso da força das águas para gerar energia é antigo e começou com a utilização das rodas d'água do tipo horizontal, que através da ação direta de uma queda d'água produz energia mecânica [...]", sendo que somente a partir do "[...] século XVIII, com o surgimento de tecnologias como o motor, o dínamo, a lâmpada e a turbina hidráulica, tornou-se possível converter a energia mecânica em eletricidade".

Assim, a energia elétrica foi massivamente utilizada e houve um crescimento repentino na criação de usinas, onde em meados do início do século XX aumentou-se o número de barragens de rios para fins de produção de energia, mas somente "[...] após a Segunda Grande Guerra é que houve um incremento das hidrelétricas como elemento do processo de industrialização das economias, que se apropriam dos rios, cachoeiras e corredeiras para gerar energia" (CAMPOS et al., 2018, p. 01).

Com isso, a forma pela qual essa geração de energia sucede-se chama a atenção de diversos estudiosos, desde os tempos pretéritos supracitados - considerando a criação e emprego dessas usinas - até a atualidade, onde parte dos impactos deletérios relativos à implantação de um projeto hidrelétrico podem ser minimizados envolvendo estudos topográficos, critérios de ordem técnica, econômica, social e ambiental, para dimensionar, adequadamente, o reservatório, o que evita ao máximo o deslocamento de populações (CAMPOS et.al., 2018), no entanto, tais impactos são existentes e latentes.

Ainda, há de se considerar, de acordo com Batista et al. (2002), que mesmo com consideráveis impactos deletérios, as hidrelétricas geram também impactos benéficos, que devem ser observados com cautela em detrimento dos negativos desde a sua fase de implementação até sua operação.

Neste contexto, considerando a barragem e usina das Três Gargantas, instalada no Rio Yang-Tsé, China, tido como a maior fábrica de energia do mundo, possuindo capacidade de geração em 22,4 mil MW, faz-se importante verificar e analisar as principais implicações, em termos de paisagem, que a obra das Três Gargantas resultou.

Em termos físicos e/ou ambientais, diversos impactos deletérios de fenômenos de considerável magnitude, como a barragem e a usina das Três Gargantas, podem ser detectados e analisados por intermédio da utilização das técnicas vinculadas às geotecnologias que auxiliam a coleta, processamento e análise da informação geográfica (MENEZES et al., 2017).

\section{OBJETIVO}

Analisar os impactos ambientais da instalação da Usina Hidrelétrica das Três Gargantas - Yiling, Hubei, China, considerando a alteração da paisagem decorrentes do processo de inundação na área de implantação do reservatório.

\section{REFERENCIAL TEÓRICO}

\subsection{0 conceito de paisagem e geoprocessamento}

A estruturação da paisagem é um procedimento essencial para a sua caracterização, onde de acordo com Maximiano (2004), a "[...] paisagem pode ser compreendida como sendo o produto das interações entre elementos de origem natural e humana, em um determinado 


\section{Revista Científica ANAP Brasil}

ISSN 1984-3240 - Volume 14, número 34, 2021

espaço. Estes elementos de paisagem organizam-se de maneira dinâmica, ao longo do tempo e do espaço". Com isso, têm-se então, as feições e condições dinâmicas, diferenciadas ou repetidas, permitindo uma classificação ao agrupar os arranjos similares e separar os diferentes. Este processo poderá ser tão detalhado ou amplo, dependendo do interesse do observador.

Para Menezes et al. (2017, p. 58), as paisagens são detectadas sob forma de arranjos espaciais com determinadas feições, onde pode ser observado o "[...] desenvolvimento de paisagens no tempo é um importante pré-requisito para entender os processos que estão ocorrendo e para o prognóstico de tendências futuras".

Diversas tarefas dos órgãos ambientais, a documentação da condição atual e a detecção de mudanças são de significado central no tocante à paisagem. Em especial a proteção ambiental, por estar relacionada ao espaço, tem a necessidade de dados espaciais e atualizados (LANG; BLASCHKE, 2009).

A aquisição de imagens orbitais através de sensores agregados em satélites demonstra um avanço da tecnologia espacial, sendo possível analisar as paisagens naturais e as suas mudanças. Diante desta possibilidade, segundo Pereira (2019, p. 19), “[...] o geoprocessamento utiliza várias técnicas matemáticas e computacionais para a coleta, tratamento e manipulação de informações espaciais", ou seja, por "meio de Sistemas de Informação Geográfica (SIG), torna-se essencial para a integração, tratamento e espacialização de dados geográficos". Sendo assim, o uso do SIG é essencial para a análise das mudanças paisagísticas, considerando as transformações do espaço temporal.

Diante disso, Oliveira e Cunha (2017), destacam a importância das técnicas de SIG na análise e estudo da degradação da paisagem natural. A partir do conhecimento obtido com as informações dos dados geoprocessados, é possível ter uma noção de como as ações antrópicas interferem na transformação de paisagens naturais. Sendo assim, utiliza-se a ferramenta SIG a fim de obter dados sobre a região estudada, podendo observar informações sobre os efeitos das ações antrópicas e contribuir para estudos de conservação dos recursos naturais.

\subsection{Barragens e reservatórios}

A barragem, de acordo com a Agência Nacional de Águas e Saneamento Básico - ANA (2020), é constituída por ser uma estrutura física que contém um determinado curso d'água. $\mathrm{E}$ por sua vez, os reservatórios são os acúmulos de água em uma determinada localidade resultante das construções dessas barragens. Sendo assim, as barragens assumem diversos usos, tais como: acumulação de água, hidroeletricidade, disposição final ou temporária de rejeitos minerais, disposição de resíduos industriais, dentre outros usos.

No entanto, em termos hídricos, caracteriza-se como sendo a principal função de uma barragem a criação de um reservatório de água, onde, próximo à barragem, o rio fica semelhante a um lago. Quanto a utilização do reservatório é múltipla e, no caso do Projeto das Três Gargantas, o intuito foi mitigar enchentes através do controle do fluxo do rio, promovido pelo reservatório e barragem, onde há o armazenamento de água para compensar as variações do fluxo do rio ao longo do ano, e as comportas da barragem se abrem ou se fecham para controlar a quantidade de água do reservatório deve passar por ela e seguir seu curso (SILVÉRIO, 2012). 


\section{Revista Científica ANAP Brasil}

ISSN 1984-3240 - Volume 14, número 34, 2021

\subsection{Correção radiométrica de imagens multiespectrais}

A correção radiométrica faz parte de um conjunto de técnicas de pré-processamento que segundo Vettorazzi (2016) utilizam-se de programas computacionais que possibilitam a conversão de dados digitais brutos em dados reparados em termos radiométricos, atmosféricos e geométricos.

Dessa forma, a correção radiométrica é empregada para a reparação de efeitos intervencionistas advindos da atmosfera e de topografia, bem como também da não calibração dos sensores que estão a bordos de seus respectivos satélites, sobre os Números Digitais ou Digital Numbers (ND), possibilitando, assim, aproximar estes dados de características biofísicas dos alvos da superfície terrestre (SILVA; VALERIANO, 2005).

Em termos mais específicos, tem-se que a natureza desses efeitos ou distorções radiométrica do Número Digital (ND), empregado também de níveis de brilho, dos pixels medidos diretamente em uma imagem derivada das respectivas fontes, segundo Watanabe, 2020:

a. Efeitos atmosféricos, que estão associados com a cena imageada;

b. Efeitos de instrumentação, que são resultantes do próprio sistema sensor e detectores de radiação.

Decorre disso então, ainda segundo Watanabe (2020), que a correção dos efeitos instrumentais, ou seja, as variações decorrentes do próprio equipamento sensor, podem ser superadas através de uma calibração radiométrica que deve ser realizada banda a banda. No caso de imagens orbitais, tem-se que levar em apreço (CHEN; HERZ, 1996; WATANABE, 2020):

a. Os detectores são elaborados para produzir uma resposta linear para a Radiação Eletromagnética - REM espectral de interesse;

b. Os respectivos detectores apresentam uma função resposta radiométrica linear, cujas características são controladas por sistemas de calibração a bordo;

c. A radiância espectral absoluta da fonte de calibração é um parâmetro pré-lançamento e assume-se que seja estável durante toda vida útil do sensor.

\section{4 Índice espectral na detecção de fenômenos naturais}

Os índices espectrais constituem-se como sendo uma ferramenta de suma importância para o sensoriamento remoto, tendo um vasto campo de aplicações, sobretudo em termos ambientais, para identificar e monitorar os diferentes alvos da superfície terrestre (SILVA et al., 2019). Dessa forma, os índices espectrais, segundo Matsuda (2020), são combinações de bandas, fundamentada no comportamento espectral de alvos específicos da superfície terrestre, utilizados para destacar aspectos característicos dos alvos na imagem.

Ainda em termos conceituais, de acordo com o glossário do Projeto de Mapeamento Anual do Uso e Cobertura da Terra no Brasil - MapBiomas (2019), índices espectrais podem ser compreendidos como sendo o efeito de operações matemáticas entre valores numéricos de pixels das bancas de uma imagem, que permitem distinguir diversos alvos e extrair informações desejadas da superfície terrestre. 


\section{Revista Científica ANAP Brasil}

ISSN 1984-3240 - Volume 14, número 34, 2021

Assim, o Quadro 1 traz a exemplificação de alguns índices espectrais com seus campos de aplicações, visando distinguir a vegetação e água, bem como sua abreviação e formação.

Quadro 1 - Exemplificação de alguns índices espectrais e seus campos de aplicação

\begin{tabular}{|c|c|c|c|}
\hline Campo de Aplicação & Índice Espectral & Abreviação & Formulação \\
\hline \multirow{2}{*}{ Vegetação } & Ratio Vegetation Index & $\mathrm{RVI}$ & $R V I=\frac{\rho_{\text {NIR }}}{\rho_{\text {red }}}$ \\
\cline { 2 - 4 } & $\begin{array}{c}\text { Normalized Difference } \\
\text { Vegetation Index }\end{array}$ & NDVI & NDVI $=\frac{(N I R-R)}{(N I R+R)}$ \\
\cline { 2 - 4 } & $\begin{array}{c}\text { Normalized Difference Water } \\
\text { Index for vegetation }\end{array}$ & NDWI & $N D W I=\frac{R_{\text {nir }}-R_{S W I R}}{R_{\text {nir }}+R_{S W I R}}$ \\
\hline Água & $\begin{array}{c}\text { Normalized Difference Water } \\
\text { Index }\end{array}$ & NDWI & NDWI $=\frac{G-4 \cdot N I R}{G+4 \cdot N I R}$ \\
\hline
\end{tabular}

Fonte: Index DataBase - IBD, 2021.

\section{MÉTODO DE ANÁLISE}

\section{1 Área de Estudo}

Este estudo foi aplicado ao barramento e à usina ou central hidrelétrica das Três Gargantas localizado no curso superior do Rio Yang-tsé, cidade de Sandouping, situada no distrito de Yiling, província de Hubei, na região centro-sudeste da China, como é observável na Figura 1.

Figura 1 - Mapa de localização da província de Hubei - China

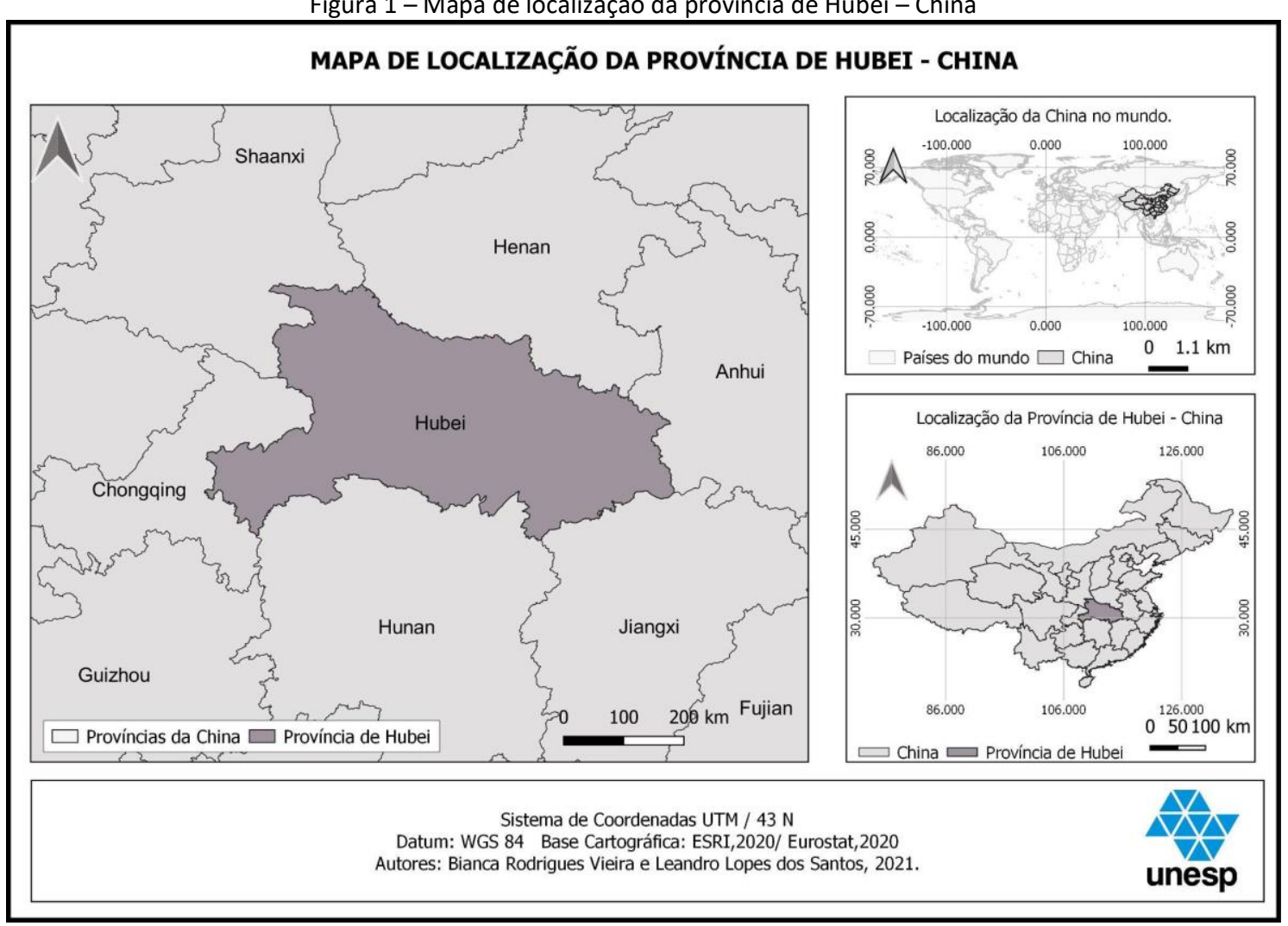

Fonte: Elaborado pelos autores, 2021. 
Situado entre as coordenadas geográficas de $30^{\circ} 49^{\prime} 42^{\prime \prime} \mathrm{N}$ e $111^{\circ} 0^{\prime} 35^{\prime \prime} \mathrm{E}$, o Reservatório das Três Gargantas, advindo do barramento das águas, possui uma área estimada de superfície de $1.045 \mathrm{~km}^{2}$, estendendo-se rio acima do respectivo barramento por $600 \mathrm{~km}$. Ainda, segundo o Serviço Geológico dos Estados Unidos ou United States Geological Survey (USGS, 2020), o comprimento das Três Gargantas é $2.335 \mathrm{~m}$ e sua altura é de cerca de $181 \mathrm{~m}$.

\subsection{Dados utilizados}

Para realizar a devida análise utilizou-se duas imagens geradas a partir dos dados obtidos pelo sensor TM/Landsat-5: bandas 2 (verde) e 4 (infravermelho próximo ou NIR), sendo essas imagens referentes aos respectivos dias: 29/12/1993 (vinte e nove de dezembro de mil novecentos e noventa e três) e 12/11/2005 (doze de novembro de dois mil e cinco).

As datas selecionadas para este estudo não foram tiradas ao acaso, uma vez que o período mais pretérito refere-se a um ano antes do início das obras para a construção destinada à barragem. E a segunda data, é posterior em uma escala temporal de aproximadamente um ano da inauguração da usina hidrelétrica.

Com isso, tem-se que as cenas obtidas nas duas datas apresentam uma diferença de aproximadamente um mês diante dos seus respectivos anos. Isso se deu, pois a imagem do mês 12 (doze) ou dezembro do ano de 2005 (dois mil e cinco) encontrava-se repleta de nuvens, impossibilitando assim, de analisar o alvo escolhido nos mesmos meses.

O download das imagens deu-se de maneira gratuita, a partir do website do Serviço Geológico dos Estados Unidos (ou United States Geological Survey - USGS), onde a Figura 2 exemplifica o processo de download da imagem referente ao ano de 1993 (mil novecentos e noventa e três), indicando assim, o mês selecionado para o estudo, assim como é admissível verificar o enquadramento que envolve a cena de interesse para este estudo.

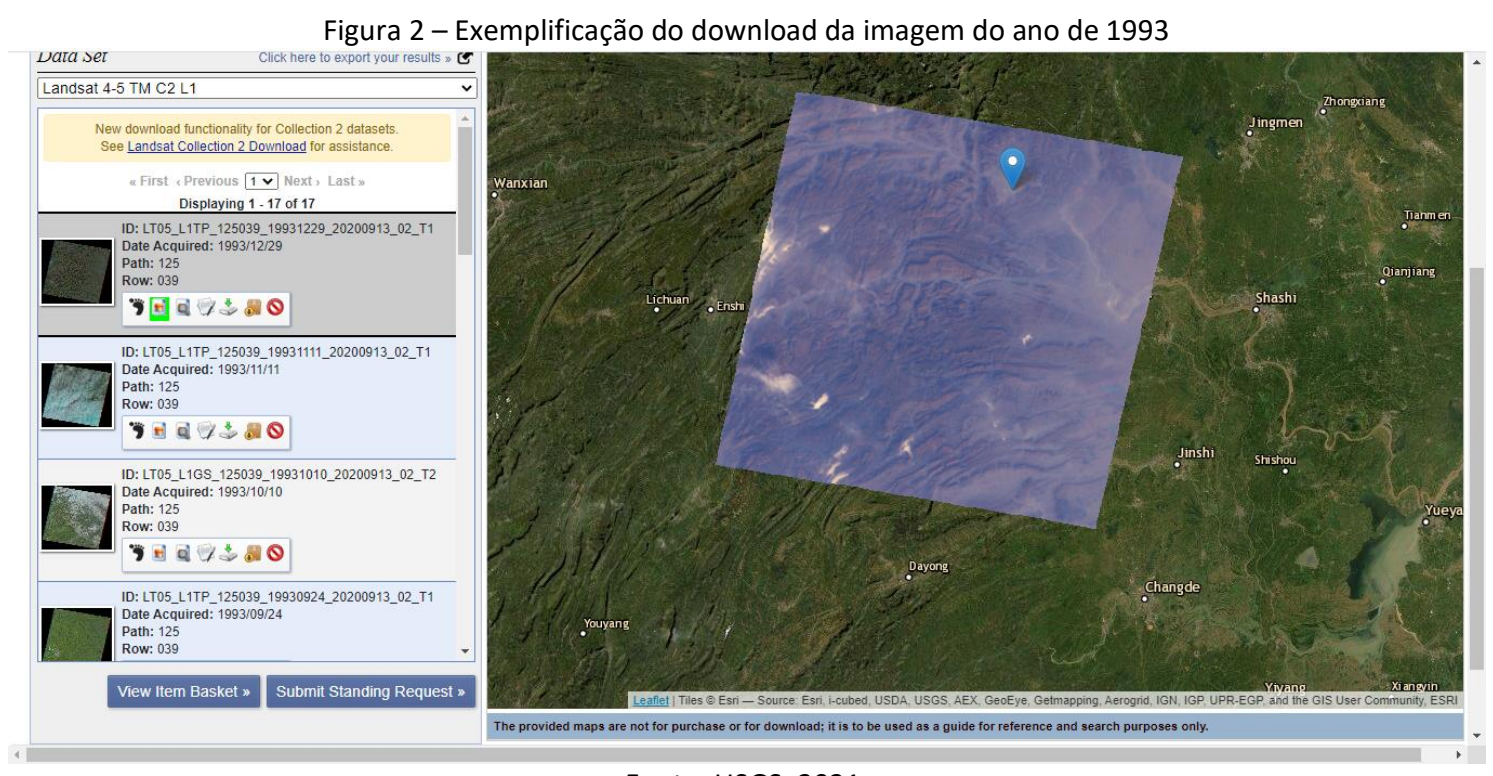

Fonte: USGS, 2021.

\subsection{Procedimentos metodológicos}

O procedimento de tratamento das imagens ocorreu por intermédio da técnica de calibração radiométrica, convertendo os Números Digitais ou Digital Numbers (ND) para 
radiância espectral no Topo da Atmosfera (TOA), usando fatores de reescalonamento da radiância contidos nos metadados (arquivo $\mathrm{MTL}$ ), mediante a utilização da equação abaixo.

$$
L_{\lambda}=M_{L} \cdot Q_{c a l}+A_{L}
$$

Onde,

$L_{\lambda}$ corresponde a radiância espectral no TOA dada em (Watts/(m.sr. $\left.\mu \mathrm{m}\right)$ );

$\mathrm{M}_{\mathrm{L}}$ ao fator multiplicativo de reescalonamento (RADIANCE_MULT_BAND_X);

$A_{L}$ ao fator aditivo de reescalonamento (RADIANCE_ADD_BAND_X);

$\mathrm{Q}_{\text {cal }}$ ao ND do pixel do produto padrão quantizado e calibrado (ND).

Com isso, em posse das imagens e de seus dados, bem como da equação supracitada, utilizou-se o software livre QGIS versão 3.10.5, em específico a ferramenta intitulada de "Calculadora Raster" - que permite inserir a equação da calibração radiométrica - para realizar a respectiva conversão de ND para radiância, onde tal conversão é dada banda a banda.

Após, para realçar ou discriminar os corpos d'água, foi-se aplicado o índice da Diferença Normalizada da Água ou Normalized Difference Water Index (NDWI), proposta por Polidorio, Imai e Tommaselli (2004), utilizando os dados de radiância. O índice NDWI utiliza-se das bandas do verde e infravermelho próximo, assim como um fator de ganho que é incorporado à banda do NIR devido a menor resposta que a água apresenta nessa banda, como observado na expressão abaixo.

$$
N D W I=\frac{G-4 \cdot N I R}{G+4 \cdot N I R}
$$

Onde,

G - Banda do verde;

NIR - Infravermelho próximo.

\section{RESULTADO}

A partir da aplicação do índice da Diferença Normalizada da Água ou Normalized Difference Water Index (NDWI) nas respectivas imagens de dezembro de 1993 (um ano antes do início da construção) e de novembro de 2005 (um ano depois da inauguração das Três Gargantas), bem como a realização da operação aritmética de subtração entre as imagens, pôde obter-se a detecção de mudança em termos paisagísticos advindos do processo de inundação na área de implantação do reservatório das Três Gargantas - Yiling, Hubei, China, como é exemplificado pela Figura 3. 
Figura 3 - Detecção de mudança na Usina Hidrelétrica das Três Gargantas

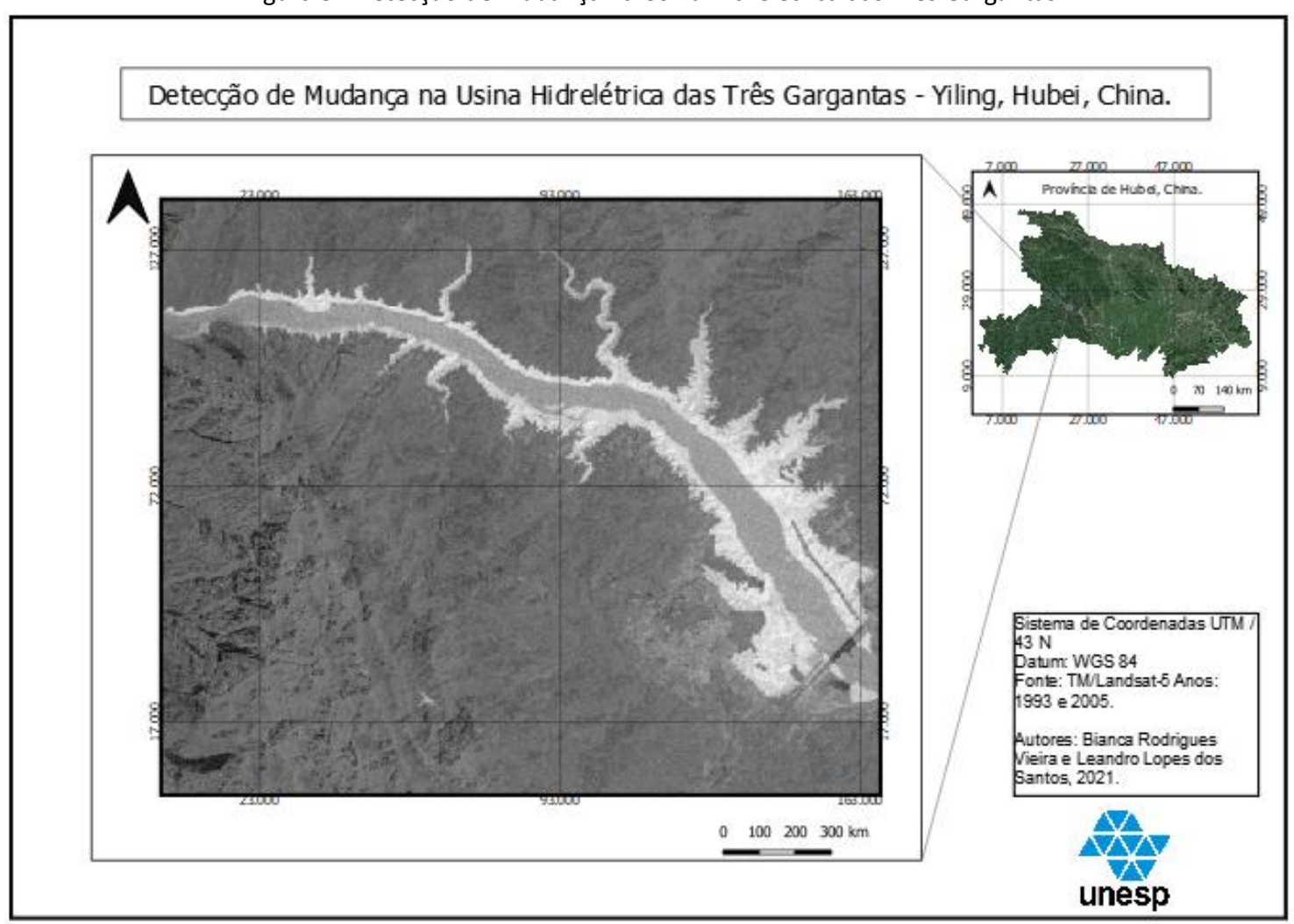

Fonte: Elaborado pelos autores, 2021.

A Figura 3 traz um satisfatório resultado no que se refere ao aspecto visual do alvo observado, podendo constatar as mudanças ocorridas no estado da paisagem, em especial no corpo hídrico. Atentando-se, portanto, ao Rio Yang-tsé em tom de cinza médio, tem-se uma visualização correspondente ao mês de dezembro do ano de 1993 e na tonalidade de cinza mais esbranquiçado, referente ao mês de novembro do ano de 2005, tem-se uma configuração de pós-construção, instalação e operação do projeto das Três Gargantas em termos de barragem, usina e volume do reservatório de água. Ainda, no canto inferior direito da imagem concebida é admissível verificar o barramento e localidade onde há a queda d'água.

Em termos visuais e comparativo, há uma flagrante mudança na geometria hidráulica do respectivo Rio Yang-tsé, manifestando uma considerável modificação na morfologia do leito do canal após a recepção do projeto das Três Gargantas, ou seja, após a concepção do barramento das águas.

Além disso, a área alagada estimada foi de $16.608 \mathrm{~km}^{2}$, onde tal análise deu-se através da utilização da ferramenta de cálculo de área nas imagens de 1993 e 2005. À vista disso, ou seja, em decorrência do respectivo barramento das águas, é possível verificar uma diminuição da composição florística que outrora foram subtraídas e/ou submersas em detrimento da instalação do projeto das Três Gargantas. Assim, os impactos aqui mencionados são individualizados, no entanto, são encadeados, onde a mera existência de um propicia a existência de outro(s). 


\section{Revista Científica ANAP Brasil}

ISSN 1984-3240 - Volume 14, número 34, 2021

\section{CONCLUSÃO}

Dessa forma, a partir deste estudo, é possível observar que a aplicação das diferentes técnicas vinculadas às geotecnologias constituem uma importante ferramenta para análise de diversos tipos de fenômenos - naturais ou de ordem antrópica. Neste caso, buscou-se detectar se houve mudanças em termos paisagísticos decorrentes da instalação da usina hidrelétrica das Três Gargantas - Yiling, Hubei, China, utilizando o índice da Diferença Normalizada da Água ou Normalized Difference Water Index (NDWI). Por meio do processamento das imagens, notou-se que sim, houve significativas mudanças ao comparar os anos de 1993 (um ano antes ao início das obras) e 2005 (um ano depois da inauguração da usina), onde a área alagada estimada é de $16.608 \mathrm{~km}^{2}$, com uma considerável perda da vegetal local e mudança na geometria do canal originário.

\section{REFERENCIAL BIBLIOGRÁFICO}

AGÊNCIA NACIONAL DE ÁGUAS E SANEAMENTO BÁSICO - ANA. 2020. Barragens e reservatórios. 2020. Disponível em: https://www.ana.gov.br/aguas-no-brasil/saiba-quem-regula/reservatorios. Acesso em: 20 jul. 2021.

BATISTA, B. M. et al. Revisão dos impactos ambientais gerados na fase de instalação das hidrelétricas: uma análise da sub-bacia do Alto Juruena - MT. Revista Biodiversidade, Mato Grosso, v. 11, n. 01, p. 69-85, 2012. Disponível em https://meioambiente.mppr.mp.br/arquivos/File/Acervo/Revisao_impactos_ambientais_fase_instalacao_hidreletri cas.pdf. Acesso em 17 de ago. de 2021.

BARBIERI, M.D. Conflitos socioambientais na construção de hidrelétricas e os dilemas da produção de energia energética: o caso das Três Gargantas (China). Revista PerCursos, Florianópolis, v. 19, n. 41, p. 28-49, set./dez. 2018. Disponível em: https://www.revistas.udesc.br/index.php/percursos/article/view/1984724619412018028/pdf. Acesso em 20 jul. 2021.

CAMPOS, L.S. et al. Os impactos na construção de usinas hidrelétricas: Um estudo de caso no Complexo de Urubupungá. In: ENCONTRO NACIONAL DE GEÓGRAFOS, 19., 2018, Paraíba. Anais [...]. João Pessoa, Paraíba, 2018, p. 1-11. Disponível em:

http://www.eng2018.agb.org.br/resources/anais/8/1533672696_ARQUIVO_Osimpactosnaconstrucaodeusinashidre letricasumestudodecasonoComplexodeUrubupunga.pdf. Acesso em 20 jul. 2021.

CHEN, S. C.; HERZ, R. Estudos Quantitativos e Calibração Radiométrica de Dados Digitais do Landsat-5. In: SIMPÓSIO BRASILEIRO DE SENSORIAMENTO REMOTO, 8., 1996, Salvador. Anais [...]. Salvador: INPE, 1996, p. 499-506. Disponível em: http://marte.sid.inpe.br/col/sid.inpe.br/deise/1999/01.29.11.31/doc/T24.pdf. Acesso em 20 jul. 2021.

INDEX DATABASE - IBD. Banco de dados de índices. 2021. Disponível em: https://www.indexdatabase.de/. Acesso em 20 jul. 2021.

MATSUDA, L. M. Transformações de imagens multiespectrais. Faculdade de Ciências e Tecnologia, Universidade Estadual Paulista "Júlio de Mesquita Filho", campus de Presidente Prudente, 2020. Disponível em: https://drive.google.com/file/d/1_XPzdarwykIKHDBzo0IEIJqC7rP4TTbt/view. Acesso em 20 jul. 2021.

LANG, S.; BLASCHKE, T. Análise da Paisagem com SIG. São Paulo: Oficina de Textos, 2009.

MAXIMIANO, L.A. Considerações sobre os conceitos de paisagem. Revista RA'EGA, UFPR, Curitiba, n. 08, p. 83-91, 2004. Disponível em: https://revistas.ufpr.br/raega/article/viewFile/3391/2719. Acesso em 20 jul. 2021.

MENEZES, S. J. M. C., et al. Geotecnologias aplicadas à gestão ambiental. Revista Diversidade e Gestão, UFRRJ, Rio de Janeiro, v. especial, p. 57-69, 2017. Disponível em: http://www.itr.ufrrj.br/diversidadeegestao/wpcontent/uploads/2017/07/05-Geotecnologias_Sady_revisado_20_05_17.pdf. Acesso em 20 jul. 2021.

OLIVEIRA, O. M. G.; CUNHA, R. D. A. O Sig como ferramenta de análise da paisagem: o caso do mangue no bairro de São Domingos em Ilhéus - BA. Revista Paisagem e ambiente, USP, São Paulo, n. 24, p. 39-48, 2007. Disponível em: https://www.revistas.usp.br/paam/article/download/85675/88436/120695. Acesso em 20 jul. 2021. 


\section{Revista Científica ANAP Brasil}

ISSN 1984-3240 - Volume 14, número 34, 2021

PEREIRA, C. B. Geoprocessamento aplicado à análise da paisagem: transformações no prolongamento da Avenida João Paulo II, Ananindeua (PA). 2019. Trabalho de Conclusão de Curso - Faculdade de Tecnologia em Geoprocessamento, Universidade Federal do Pará, campus de Ananindeua, Pará, 2019. Disponível em: https://bdm.ufpa.br:8443/jspui/bitstream/prefix/1024/1/TCC_GeoprocessamentoAplicadoAnalise.pdf. Acesso em Acesso em 20 jul. 2021.

POLIDORIO, A. M.; IMAI, N. N.; TOMMASELLI, A. M. G. Índice indicador de corpos d'água para imagens multiespectrais. In: SIMPÓSIO DE CIÊNCIAS GEODÉSICAS E TECNOLOGIAS DA GEOINFORMAÇÃO, 01., 2004. Recife. Anais [...]. Disponível em: https://www3.ufpe.br/cgtg/ISIMGEO/CD/html/Fotogrametria\%20e\%20Sensoriament. Acesso em 20 jul. 2021.

PROJETO DE MAPEAMENTO ANUAL DO USO E COBERTURA DA TERRA NO BRASIL - MapBiomas. Glossário. 2019. Disponível em: https://mapbiomas.org/glossario. Acesso em 20 jul. 2021.

SILVA, B. S. G.; VALERIANO, D. M. Correção atmosférica e topográfica de imagens de satélite em terrenos montanhosos. In: SIMPÓSIO BRASILEIRO DE SENSORIAMENTO REMOTO, 12., Goiânia, 2005. Anais [...]. Goiânia: INPE, 2005. p. 3.587-3.594. Disponível em:

http://marte.sid.inpe.br/col/ltid.inpe.br/sbsr/2004/11.21.18.37.34/doc/3587.pdf. Acesso em 20 jul. 2021.

SILVA, R. C. F. et al. Análise comparativa de índices espectrais para a extração automática da lâmina d'água em imagem do satélite Landsat- 8 Oli. In: SIMPÓSIO BRASILEIRO DE SENSORIAMENTO REMOTO, 19., São José dos Campos, 2019. Anais eletrônico [...]. São José dos Campos: INPE, 2019. Disponível em:

https://proceedings.science/sbsr-2019/papers/analise-comparativa-de-indices-espectrais-para-a-extracaoautomatica-da-lamina-d-agua-em-imagem-do-satelite-landsat-8oli. Acesso em 20 jul. 2021.

SILVÉRIO, M.S. Projeto Três Gargantas: cidade e território na China. 2012. Trabalho de Graduação - Faculdade de Arquitetura e Urbanismo, Universidade de São Paulo, São Paulo, 2012. Disponível em:

http://www.metropolefluvial.fau.usp.br/downloads/projetos/GMF_ensino-tfg_strassacarpa.pdf. Acesso em 20 jul. 2021.

UNITED STATES GEOLOGICAL SURVEY - USGS. Earth explorer. 2021. Disponível em: https://earthexplorer.usgs.gov/. Acesso em 20 jul. 2021.

UNITED STATES GEOLOGICAL SURVEY - USGS. Three Gorges Dam: the world's largest hydroelectric plant. 2020. Disponível em: https://www.usgs.gov/special-topic/water-science-school/science/three-gorges-dam-worldslargest-hydroelectric-plant?qt-science_center_objects=0\#qt-science_center_objects. Acesso em 20 jul. 2021.

VETTORAZZI, C. A. Processamento de imagens. Escola Superior de Agricultura "Luiz de Queiroz", Universidade de São Paulo. 2016. Disponível em:

http://www.leb.esalq.usp.br/leb/disciplinas/Topo/leb450/Vettorazzi/LEB450_Processamento_de_Imagens.pdf. Acesso em 20 jul. 2021.

WATANABE, F. S. Y. Correção radiométrica de imagens multiespectrais. Faculdade de Ciências e Tecnologia, Universidade Estadual Paulista "Júlio de Mesquita Filho", campus de Presidente Prudente, 2020. Disponível em: https://drive.google.com/file/d/1Qnc7YEKE3Du0ZZVLbzCaJwmvtLW02sxd/view. Acesso em 20 jul. 2021. 